\title{
International Journal of Research in Engineering and Innovation
} (IJREI)

journal home page: http://www.ijrei.com

\section{ORIGINAL ARTICLE}

\section{A study on remote sensing data integrating multi spectral and their implementation in image analysis: a case study on metro train project of Meerut city}

\section{Antima, Sandeep Rana}

Department of Computer Science and Engineering, JP Institute of Engineering \& Technology, Meerut, India

Article Information

Received: 16 January 2022

Revised: 07 February 2022

Accepted: 24 February 2022

Available online: 23 February 2022

Keywords:

Remote sensing data

Satellite sensor

Multi-spectral images

NATM Technology

\begin{abstract}
In the field of satellite image processing, this work focuses on the Image Analysis of Remote Sensitivity which includes Spectral, Temporary, and Spatial Properties. We used multi-spectral remote sensor data to determine the spectral signature of the various objects in Meerut to separate the earth cover, how land use varied over time, and to perform interim analyzes to assess the climate impact on the area. Some combinations of remote sensor bands are useful for splitting the earth cover. The spatial distribution of land cover areas such as roads, urban areas, agricultural land, and water resources can be easily assessed by calculating their General Plant Diversity Index (NDVI). We conducted a groundbreaking survey to determine the NDVI boundary values, and based on that, we calculated the False Color Combination (FCC) of items in the category. Separated information may be used for municipal planning and management. The aim of the longterm thesis is to develop land use patterns to grow the city's sustainable economy and environment.

(C)2022 ijrei.com. All rights reserved
\end{abstract}

\section{Introduction}

NASA originally owned satellite sensors; however, the responsibility for the Landsat program was transferred to NOAA in 1983. A few factors contribute to the success of Landsat, which includes a combination of sensors with spectral bands designed for Earth observation; workplace adjustment; and top location (swath width and re-visit time). The extended history of this program has resulted in a massive collection of global resource data, which allows for long-term monitoring and historical and research records [1]. All Landsat satellites are set at sun-synchronous, near-polar orbits. The first three satellites (Landsats 1-3) are located at an altitude of about 900 $\mathrm{km}$ and have intervals of 18 days, while these satellites are located at altitudes of about $700 \mathrm{~km}$ and have to be visited over 16 days. For optimal lighting conditions, all Landsat satellites cross the equator in the morning. The Landsat satellite series handles a variety of sensors, including Return Beam Vidicon (RBV) camera systems, Multispectral Scanner (MSS), and Thematic Mapper (TM). The Multispectral Scanner (MSS), and later the Thematic Mapper, were the most famous Landsat instruments in the early days (TM) [2-5]. Each of these sensors collects data over a distance of $185 \mathrm{~km}$, with an area defined as $185 \mathrm{~km}$. In four spectral bands, MSS receives electromagnetic radiation across the Earth's surface. Each band has a $60 \times 80$-meter spatial adjustment and a 6-bit (64-digit) radiometric resolution. A line scanning device with a rotating mirror is used for hearing. For each sweep west and east of the scanner, six scanning lines are collected simultaneously.

Corresponding author: Antima

Email Address: sharmaantima989@gmail.com

https://doi.org/10.36037/IJREI.2022.6107 


\section{Study area}

Our research focuses on Meerut city, as indicated on the Meerut district map. Meerut is an affluent and major city in U.P. It has a population of around 1.2 million inhabitants. The city is historically noteworthy as the start of the Indian resistance to British rule, but it is currently evolving into an economic hub for the surrounding region. The construction sector in Meerut has exploded, and the city now has a slew of new buildings, shopping malls, and apartments. Meerut is India's leading supplier of recreational goods and a significant of musical instruments manufacturer.

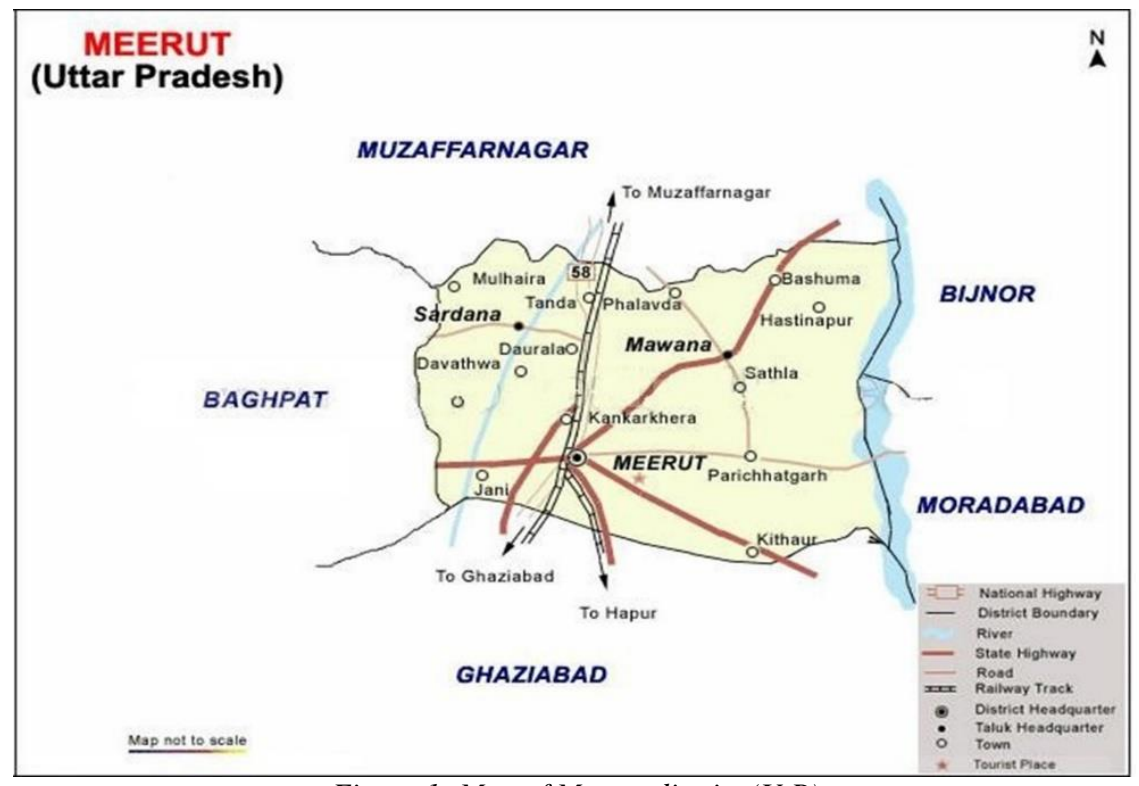

Figure 1: Map of Meerut district (U.P)

\subsection{Soil and climate}

According to the National Bureau of Soil Survey and Land Use Planning in Nagpur, the area is part of Agro-ecological Region 4. PDCSR research farm soils are typical of the region, being neutral to slightly alkaline and belonging to the Typic Ustochrept group. Meerut has a semi-arid subtropical climate with extremely scorching summers and bitterly frigid winters. May-June is the hottest month, with maximum temperatures reaching $45-46{ }^{\circ} \mathrm{C}$, while December-January is the coldest month of the year, with minimum temperatures frequently falling below $5{ }^{\circ} \mathrm{C}$. The average annual rainfall is 862.7 millimeters, with the northwest monsoons accounting for 75$80 \%$ of the total [6].

\subsection{Multi-spectral images from LISS 4 MX sensor}

Scene Corners:

North East Longitude: 77.923

North West Longitude: 77.656

North East Latitude: 29.131

North West Latitude: 29.192

South West Longitude: 77.593

South West Latitude: 28.977

South East Longitude: 77.86

South East Latitude: 28.915

Scene Centre:

Latitude: 29.054
Longitude: 77.757

(Dated 09 January 2018)

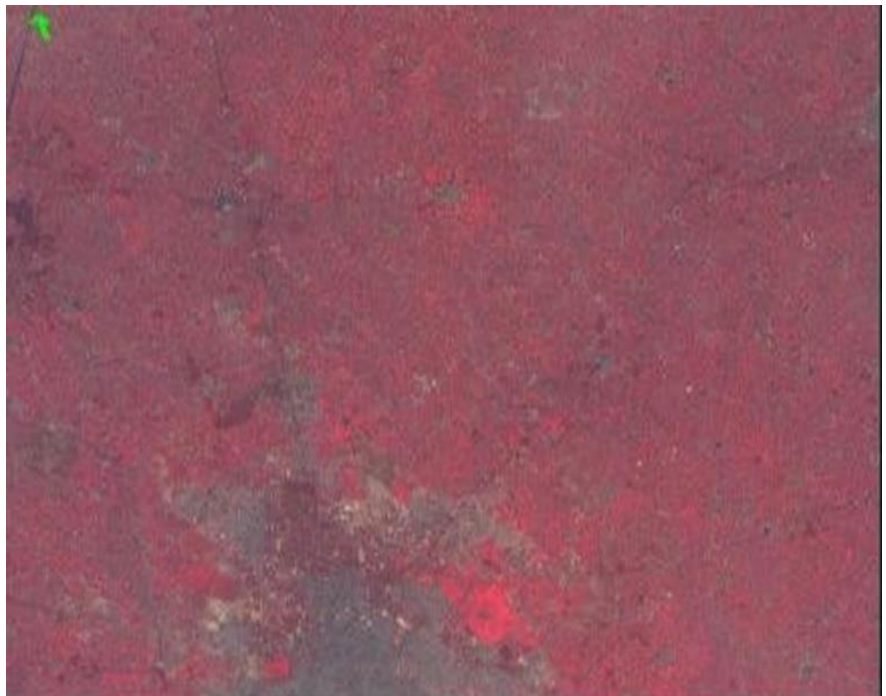

Figure 2: Multi Spectral Image of Meerut city

\subsection{Satellite view of Meerut city}

Google Earth has provided us with satellite photographs of the Meerut city region; all of the images are in the visible spectrum with high resolution. These photos were obtained to ensure that the survey locations' latitudes and longitudes were exact and to 
demonstrate that our analysis was accurate [7-10].

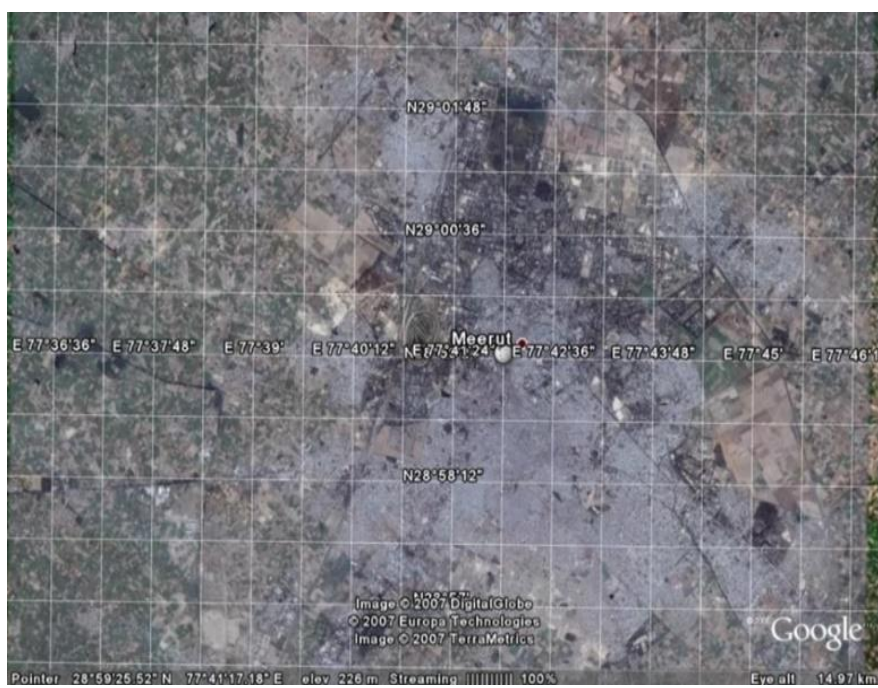

Figure 3: A satellite view of Meerut city

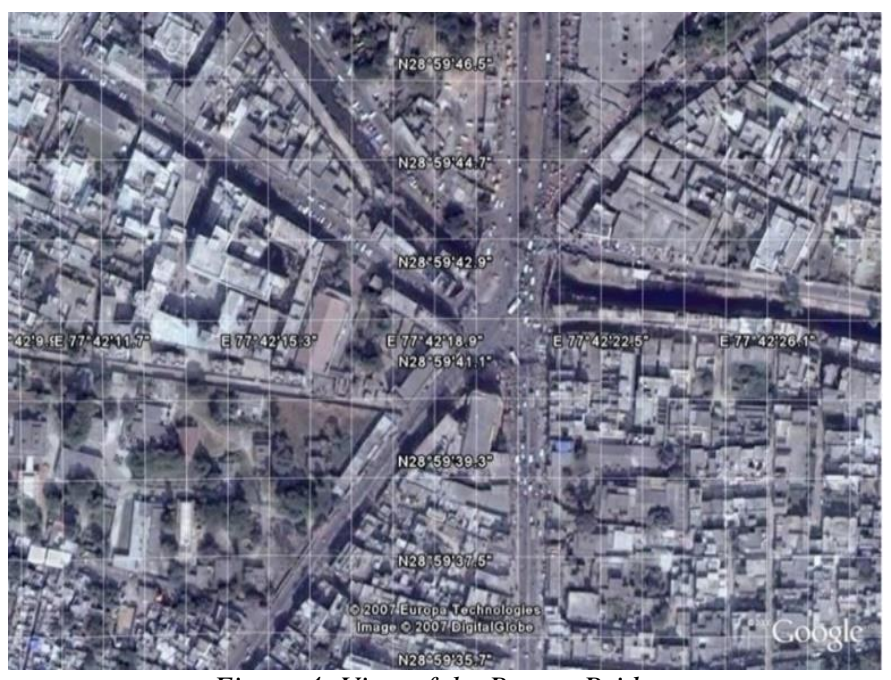

Figure 4: View of the Begum Bridge

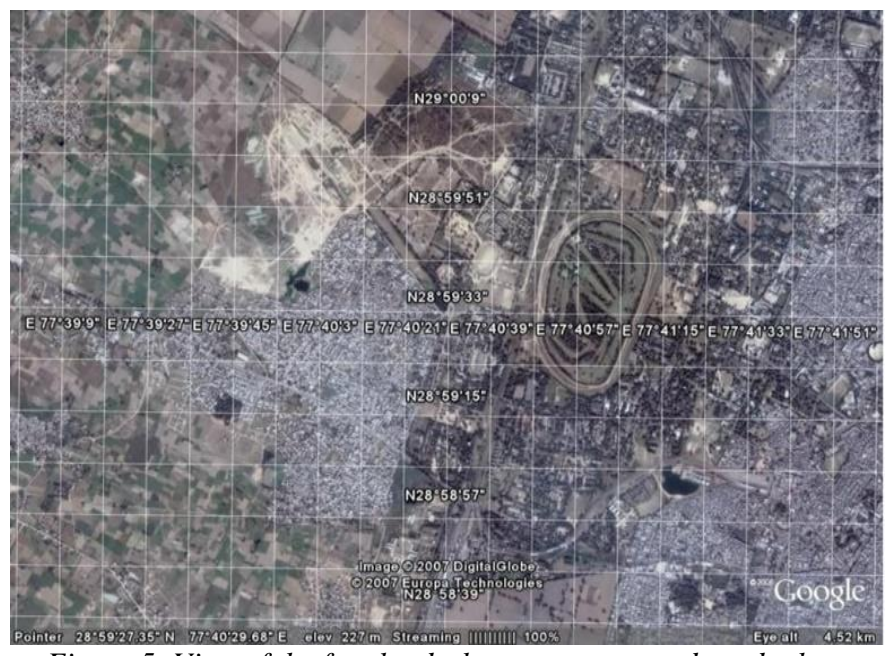

Figure 5: View of the free lands, houses, trees, roads and other objects

\section{Methods of analysis}

We must separate the different bands of the photos in order to analyze the multispectral photographs. And after collecting a separate image of each brand, we must examine the energy response of each object in the different bands. This allows us to quickly determine which bands are best for which objects. We must determine the right relationship of energy response among the various spectral bands in order to obtain the spectral signature of each object; each object has its own spectral signature by which we may identify the object We employed the NDVI to classify the items in our investigation by establishing a link between energy response and spectral bands. Because the energy response of plants in the infrared band is very good, we utilized photos with the infrared band to identify the plants in our study. Plants are very important for the health of the environment, thus we used images with the infrared band to identify the plants. However, distant sensing scenarios are more complicated, as the object's energy response may not be appropriately received because the environment absorbs the produced energy; the fault could be due to geometric and radiometric distortions. As a result, we must make specific changes.

\subsection{Corrections applied to raw data}

The National R.S Agency from which we acquired the multi spectrum photos, has already completed all radiometric and geometric corrections.

\subsection{Radiometric Corrections}

IRS Satellite sensors are made up of linear arrays of Charge Coupled Devices (CCD) with varying numbers of detector elements. The responses of the various elements of any of the arrays will not be identical. The method of radiometric correction normalizes these reactions using laboratorymeasured radiometric calibration values. The procedure for performing the radiometric adjustment is as follows:

- Line loss correction

- Failed/degraded detector correction

- Framing of required scene

- Detector normalization

\subsection{Geometric Corrections}

The following aberrations in the data received by satellite necessitate geometric corrections:

- Distortion caused by the satellite's relative velocity concerning the earth.

- Distortion caused by the curvature of the Earth.

- Tilt angle distortion causes panoramic distortion.

Corrections are required to remove the above-mentioned distortions and project them onto the user-specified map projection in the desired datum. In two processes, the 
distortions in the satellite data are corrected:

- By establishing a mapping between the user-defined output areas.

- By translating the input data into the output space that has been defined.

\subsection{Atmospheric corrections}

Because the released energy can be absorbed by the environment, the energy response of the objects may not be received correctly. We can minimize the error by using the ground survey. Atmospheric effects have an effect. We discovered the threshold values of NDVI in sample sites for each object in a certain climate condition because we are employing NDVI data for object categorization in our study. After that, we've generalized the values throughout the entire image [11].

\subsection{Analysis of the multi spectral images of $09^{\text {th }}$ January}

Step 1: We obtained two nearby photos of the Meerut city region, and we concatenated them using MATLAB. We next eliminated the unwanted areas of the photographs till we arrived at the image displayed in Fig. 6.

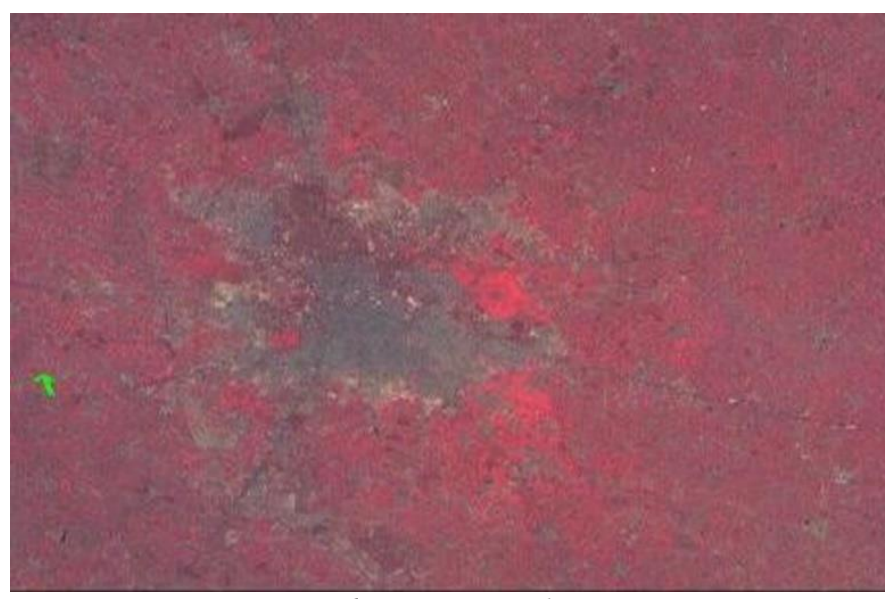

Step 2

Figure 6: Concatenated Image

We've gotten color photos with RGB components; R stands for near infrared, $G$ for red, and B for green in the images. The three different views of the different bands were obtained using MATLAB.

As can be seen from the above photographs, the energy response in the infrared band is adequate, followed by the energy response in the green band, but the energy response is the lowest in the red band, showing that the vegetation component is quite dominant.

Step 3

Our goal now is to determine the NDVI values of the provided image after obtaining photographs of the various bands.
NDVI $=\frac{\text { NIR-RED }}{\text { NIR+RED }}$

NDVI values of each pixel were observed by MATLAB, and the range of NDVI values lies between -1 to +1 . We have converted this range from 0 to 200 for the making image.

NDVI image value $=($ NDVI value +1$) \times 100$

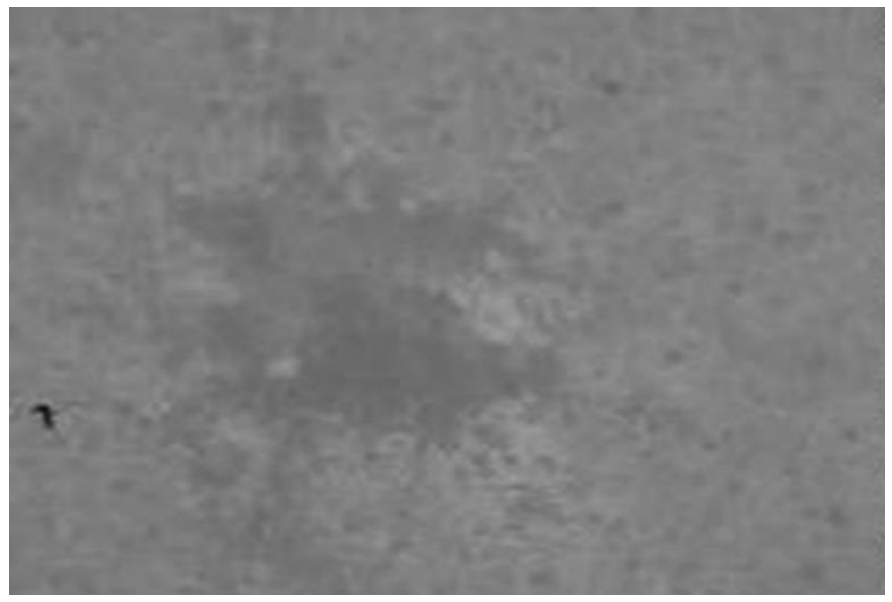

Figure 7: NDVI image

Step 4

Following the NDVI image, the next goal was to obtain categorized photos of the region. We utilized Google Earth to collect the proper longitude and attitude values of the survey region, which then used to identify the survey locations in the multispectral photos, and we conducted a ground survey at several locations throughout the city to get these photographs. I was able to determine the NDVI range for each object using the ground survey. NDVI values are in between 0 and 1 for vegetation. But most of the concentration of the vegetation is in the range of 0.2 to 1 [12-14].

$(\operatorname{NDVI}(\mathrm{m}, \mathrm{n})<1)$ and $(\operatorname{NDVI}(\mathrm{m}, \mathrm{n})>=0.2)$

- Values of NDVI are in the range between 0 and 0.2 for manmade structure.

$(\operatorname{NDVI}(\mathrm{m}, \mathrm{n})<0.2)$ and

$(\operatorname{NDVI}(\mathrm{m}, \mathrm{n})>=0.0) \&(\mathrm{red}(\mathrm{m}, \mathrm{n})>80) \&(\mathrm{nir}(\mathrm{m}, \mathrm{n})$ $<160)$

- Values of NDVI are in the range between 1 and 0 for the roads.

$(\operatorname{NDVI}(\mathrm{m}, \mathrm{n})<0.2) \&(\mathrm{NDVI}(\mathrm{m}, \mathrm{n})>=0.0) \&$ $((\operatorname{nir}(\mathrm{m}, \mathrm{n})>115) \&(\operatorname{nir}(\mathrm{m}, \mathrm{n})<125)) \&(\operatorname{red}(\mathrm{m}, \mathrm{n})<85)$

- Values of NDVI are in the range between 0 and 0.1 for free land.

$\operatorname{NDVI}(\mathrm{m}, \mathrm{n})<=0.1)$ and $(\operatorname{NDVI}(m, n)>0.0) \&(\operatorname{red}(m, n)>120)$

- Values of NDVI are in the range between -1 to 0 for water. $(\operatorname{NDVI}(m, n)<0.0)$ and

$\operatorname{NDVI}(m, n)>=-1)$ 

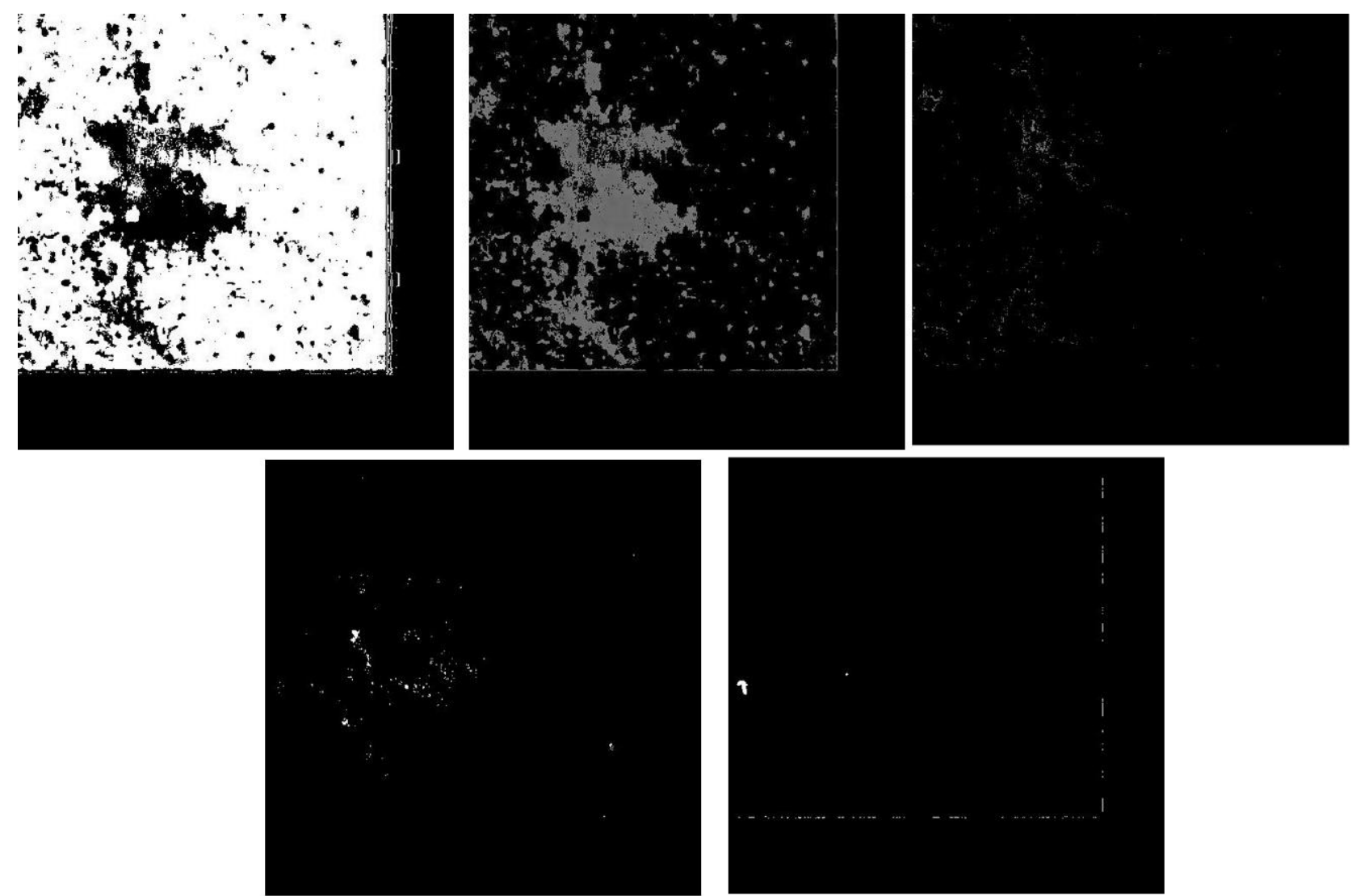

Figure 8: Images of the different components as $(a)$ vegetation $(b)$ structures $(c)$ roads $(d)$ Free land $(e)$ water resources

Step 5

Construction of the false color composite.

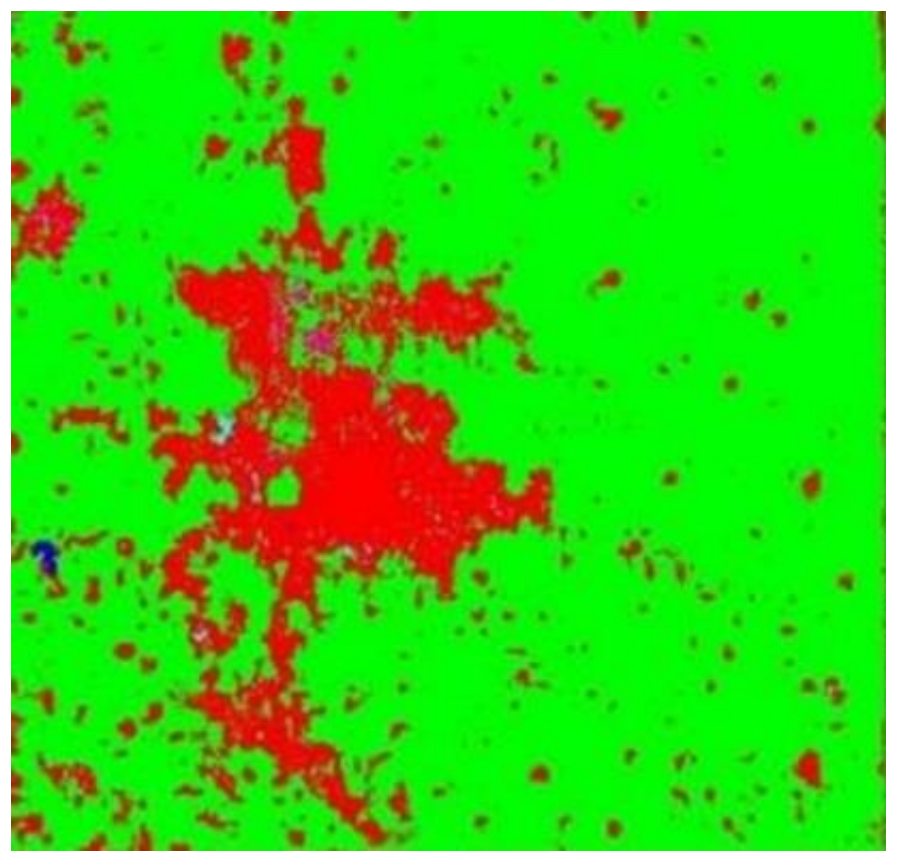

Figure 9: FCC Image of 9th January 2019

\subsection{Temporal analysis of the multi-spectral images}

When comparing the two NDVI photos, it is evident that the NDVI image of 06 September 2019 is substantially brighter than the NDVI image of 09 January 2006. That is correct. The average NDVI value in September is greater than the average NDVI value in January. It shows that flora components are much more dominating than others; in August and September, there was a lot of rain, thus the greenery was at its peak. Because of atmospheric impacts, vegetation classification in September begins with a 0.35 NDVI value, but in general, in a clear atmosphere, this threshold value is substantially lower. Which we can see in the image of the month of January as its threshold value is 0.2 . When we look at the structures photographs, we can notice in the lower right corner of the image that there are more structures in September than in January, indicating that advancements are taking place in those locations.

\subsection{Accuracy of results}

We discovered the particular ranges of RED, NIR, and NDVI for all of the components in order to construct the FCC images, but because several components were present in various ranges of all of these parameters, we determined the ideal values for minimizing the inaccuracy based on ground surveys. As a 
consequence, we discovered that our research is accurate up to 90 to 95 percent in the case of vegetation and about 85 to 90 percent in the case of structures, but only 60 to 70 percent in the case of roads, free lands, and water.

\section{Design and security of tunnel for metro train.}

The Metro Train project involves a variety of engineering disciplines, including all engineering branches. However, in this article, we will discuss project reports pertaining to civil engineering and computer engineering. The Railway Track/Road is where we begin. A railway track network is a positive-weighted graph (a graph is an ordered pair $G=(V, E)$ consisting of a set $\mathrm{V}$ of vertices, nodes, or points and a set $\mathrm{E}$ of edges, arcs, or lines) [15-17]. The graph's edges indicate road segments between two junctions, while the nodes represent road intersections. The weight of an edge can reflect the length of a connected road segment, the time required to traverse the segment or the cost of traversing the section. One-way streets can also be modeled using directed edges. For long-distance travel, such graphs are unique in that some edges are more significant than others (e.g. highways). The concept of highway dimension has been used to codify this attribute. There is a slew of algorithms that make use of this fact and, as a result, can compute the shortest path much faster than on ordinary graphs. These algorithms all work in two stages. The graph is preprocessed in the first phase without knowing the source or target node. The query phase is the next step. The source and target nodes are known at this point. The preprocessing phase can be done once and applied to a high number of queries using the same road network [43] because the road network is unchanging. The shortest path on Europe's or America's road networks may be computed in a fraction of a microsecond using the hub labeling algorithm, which has the fastest known query time. Other methods that have been employed include: Labeling. Reach based Pruning, Transit Node Routing

ALT, Contraction hierarchies, Arc Flags

\subsection{Basics need of tunnel}

Tunnel Technology is a tunnel dug through surrounding soil and enclosed save for the entry and exit points, which are normally at opposite ends. Even if some modern tunnels use immersed tube building techniques rather than classic tunnel boring methods, a pipeline is not a tunnel. A tunnel can be used for both pedestrian and rail or canal transportation. Tunnels are typically used as the primary components of a rapid transportation system. Some tunnels are irrigation systems, transporting water to dwellings or hydroelectric dams, while others are sewers. Utility tunnels convey steam, chilled water, electrical energy, and communications cables while also connecting structures to make people and equipment mobility easier.

\subsection{NATM Technology}

The New Austrian Tunnelling Method (NATM) stands for "Advanced of Tunnel Technology." This is the traditional method of tunnel excavation, commonly referred to as sequential excavation. Mr. Rabcewicz utilized it for the first time in Austria in 1962. It was previously utilized at MMRC (India) at Chawdi bazaar, Buddha Jayanti Park. NATM is commonly utilized nowadays in regions where tunneling with Tunnel Boring Machines is not practicable. Tunneling is accomplished using NATM technology, which entails either mechanical excavation or controlled blasting. The earth is excavated first, and a primary lining of rock bolts, wire mesh, steel girders, and shotcrete are used to stabilize the soil according to geological strata. After that, a final 400-mm-deep concrete liner will be installed using M-40 concrete grade [18]. During excavation, sophisticated devices such as an inclinometer, an extensometer, a load cell, and others are used to measure every movement of the surface.

\subsection{Tunnel terminology}

Tunnels are typically long and thin, with a length greater than twice their diameter, while shorter excavations, such as cross passages among tunnels, can be made. A tunnel's definition varies widely from one source to the next. A road tunnel is defined as "an underground roadway structure covered for a distance of 150 meters or more" in the U.K. According to the National Fire Protection Association (NFPA), a tunnel in the United States is "a subterranean construction having a design length larger than 23 meters and a diameter greater than 1,800 millimeters". In the U.K, a subway is a pedestrian, cycling, or animal tunnel beneath a road or railway, whereas an underground railway system is called the "Underground". A bridge, or an aqueduct if passing under a canal, is the site where a canal, railway, road passes beneath a footpath, cycling path, or another road or railway. It may be referred to as an underpass when it is vital to emphasize that it is passing beneath a railway, however the formal name for crossing beneath a railway is an under bridge. Whether or whether it crosses under another piece of infrastructure, a lengthier underpass containing a canal, and is sometimes referred to as a "tunnel." Whatever method of transportation it serves, an underpass of any length beneath a river is commonly referred to as a "tunnel."

\subsection{Geotechnical investigation and design}

For a big tunnel project, drill samples, as well as other geophysical technologies, should be employed to investigate the ground conditions. The risk of encountering unexpected ground conditions can be reduced by carefully choosing machinery and techniques for excavation and logistical support. The vertical and horizontal alignments might be selected during route choice to take advantage of the favorable water and terrain conditions. 


\subsection{Geotechnical factors}

"Stand-up time" refers to the amount of time a newly excavated hollow can maintain itself without any extra constructions. Engineers can use this value to determine how much an excavation can continue before additional support is needed, affecting construction speed, efficiency, and cost. The longest stand-up time is found in specific rock and clay combinations, while sand and fine soils have a much lesser stand-up time.

- Tunnel construction necessitates groundwater control. When water rushes into a tunnel or vertical shaft, it reduces the time it takes for the excavation to rise, making it unstable and potentially deadly. Installing dewatering pipes into the ground and just pumping the water out is the most popular method of managing groundwater. Earth freezing, which entails burying pipes around the excavation and cooling them with a particular refrigerant fluid, is a highly effective but expensive technique. The ground around each pipe freezes, thereby closing the region and preventing water from entering until a permanent structure can be constructed.

- The tunnel's cross-sectional shape is also essential in determining stand-up time. A tunnel excavation that is wider than it is tall will struggle to maintain itself, reducing the time it takes to rise. A square or rectangular excavation appears to be more difficult to produce selfsupporting due to the concentration of stress at the corners.

\subsection{Project Planning and Cost Estimates}

The construction of tunnels frequently demands the use of public funds. When it comes to planning or building a tunnel, economics is a critical factor to consider. Civil engineers frequently use project management techniques when constructing a large construction. Understanding how long a project will take, as well as how much personnel and supplies will be needed, is crucial to project planning. The project's length must be determined using a work breakdown structure (WBS) and the perilous path technique (CPM).

\subsection{Construction of Tunnel}

Tunnels can be made of a variety of materials, from soft clay to hard rock. The depth of the tunnel, the length and width of the tunnel drive, groundwater conditions, ground conditions, tunnel retention, end-use and position of the tunnel, and adequate risk management all contribute to the construction of the tunnel. procedures. Three basic methods of tunnel construction are widely used:

- A tube tunnel lowered into a body of water and laid on or buried close beneath the water's surface.

- An underground tunnel that was constructed without the need to remove the ground above it. They feature a circular or horseshoe cross-section in most cases.

- A cut-and-cover tunnel is one that is dug and then covered in a shallow trench.

\subsection{Cut-and-Cover Method:}

The trench is dug and roofed with a support system that is strong enough to withstand the load of what should be placed above the tunnel in this simple way to build shallow tunnels. There are two basic types of cutting and cover.

\subsubsection{Bottom-up method}

A tunnel is built inside a ditch that has been dug with any ground support required. In tunnel, situ concrete, preconstructed concrete, precast arches, or metal arches can be used; in the early days, bricks were used. The trench is then carefully filled back and the upper surface is restored.

\subsubsection{Top down Method}

The side support walls and locking beams are constructed from the ground level using a slurry wall or pile for boredom. Deep drilling can be used to build a tunnel roof, which can be constructed of pre-installed planks or in situ concrete. Then the top area is changed, with no entry points. As a result, roads, services, and other features can be restored as quickly as possible. Next a permanent tunnel roof is dug, and a base slab is built under it. Deep tunnels are dug, usually with tunnel protection, while smaller channels are cut and cover (or dipped tube under water). Both strategies are effective at intermediate levels. Underground municipal stations, such as London's Canary Wharf station, often use large cut-out boxes and covers. To save money, ticket halls, station halls, passenger entry, and emergency exits, ventilation and smoke control, staff quarters, and equipment rooms can all be built on two levels.

\subsection{Disadvantage of Cut-and-Cover}

A disadvantage of cut-and-cover construction is a significant disturbance it causes at the surface level. As a result of this, and the advent of electric traction, the London Underground transitioned to deeper bore tunnels towards the end of the nineteenth century.

\subsection{Tunnel Boring machines (TBM)}

In Fig. 10, TBM and support systems are used to automatically perform all tunneling work, reducing the cost of the tunnel. In some urban applications, tunnel drilling is seen as a quick and inexpensive way to build railways and roads. Compulsory purchase of property, as well as long-term planning questions, is no longer required. TBMs have two disadvantages: the difficulty of transporting large TBM to the tunnel construction site, or (alternatively) the high cost of integrating TBM into the site, usually within the boundaries of the tunnel being constructed. 


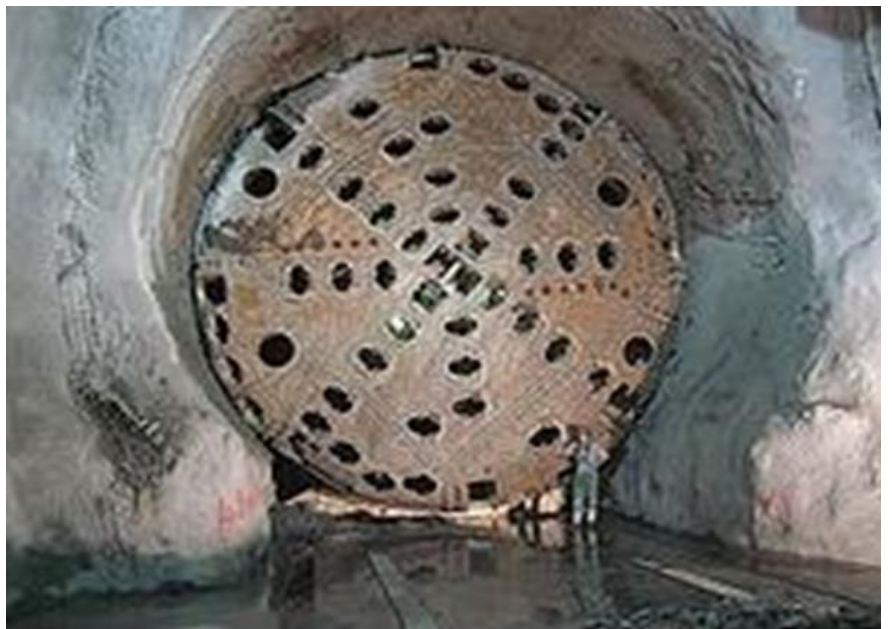

Figure 10: Tunnel Machines

\subsection{Sprayed concrete technique}

The New Austrian Tunneling Method (NATM) is a standard engineering method that provides secure linear support using mathematical and empirical data. It first appeared in the 1960s. The basic idea of this technology is to apply geological rock mass pressure to stabilize the tunnel by providing controlled comfort and redistribution of pressure on the surrounding rock, preventing full loads from being placed on the foundations. Geotechnical parameters are used to determine the best part. The excavation is protected by a layer of reinforced concrete, commonly known as shotcrete. Metal bows, rock bolts, and mesh are among the many support options.

\subsubsection{Pipe Jacking}

Pipe jacking uses electric jugs to drive pipes specially designed on the ground behind TBM or shield. This method is widely used to build tunnels under existing buildings such as car lanes and trains. The syringes are usually small holes with a diameter of about $3.2 \mathrm{~m}$.

\subsubsection{Box jacking}

Box jacking or Pipe jacks have a much narrower span than jack boxes, with some covering more than 20 meters. The front of the jacked box normally has a cutting edge, and spoil is regularly extracted from within the box with an excavator.

\subsubsection{Temporary way}

It is common to build temporary tracks during tunnel construction, especially to transport excavated debris, and is usually a small gauge so that you can double track, allowing empty and loaded trains to operate simultaneously. The temporary route is eventually replaced by a permanent route, which is why "each route" is used.

\subsection{New Austrian tunneling (NATM) method}

The New Austrian Tunneling Method (NATM), commonly referred to as the Sequential Excavation Approach (SEM), is a common method of modern tunnel construction. The strategy gained prominence in the 1960s thanks to the work of Ladislaus von Rabcewicz, Leopold Müller, and Franz Pacher in Austria between 1957 and 1965. To distinguish it from the traditional Austrian drawing method, it was given the moniker NATM. The main difference between this new type of tunnel and the previous methods is the financial savings obtained by relying on the internal rock mass of the natural support for the tunnel.

\subsubsection{Principle of NATM}

The NATM blends rock mass behavior under load with construction performance monitoring. By providing optimum support depending on observed ground conditions, the NATM has been dubbed a "design as you go" method. It's more accurately defined as a "design as you monitor" strategy, as it's based on observed lining convergence and divergence, as well as mapping of current rock conditions. It isn't a collection of distinct excavation and support methods.

\subsubsection{NATM has seven elements}

Utilization of native rock mass strength: This depends on the internal strength of the surrounding rock mass to be maintained as a key component of the tunnel support. The main purpose of the support is to allow the rock to support itself.

Shotcrete protection: To the maximum extent possible, loose and large rock flexibility should be avoided. This is done by applying a small shotcrete coat to the face after it has been improved.

Monitoring and measurement: The potential for aging in mining should be monitored closely. The installation of advanced measuring machines is required by NATM. Boreholes, liner, and soil are all contained. Additional support is built only if necessary in the event of a detected movement, reducing the total cost of the project.

Flexible Support: The mainliner is thin, showing the latest strata conditions. The replacement for the active support is used instead of a thick concrete line, and the tunnel is reinforced with a flexible combination of rock bolt, wire mesh, and steel ribs.

Inverted closure: Most importantly in a soft area, the lower part of the tunnel should be closed immediately to form a loadbearing ring, which benefits from the natural strength of the piles of rocks around the tunnel.

Contract arrangements: It is possible to adjust the support and construction method because NATM relies on monitoring statistics, but only if the contract system allows it. 


\subsection{Key features of the NATM design}

- Ground strength mobilization is accomplished by enabling controlled ground deformation.

- Primary Support First is included with sufficient load fluctuations in ground conditions and timed to accommodate land degradation.

- Tools installed to track damage to the initial support system and to direct the repair of the project and the initial support digging process.

- The tunnel is excavated and maintained in sequence, with the excavation sequence adapting to the specific rock conditions encountered.

- The first soil foundation is provided with shotcrete in combination with fiber or welded-wire fabric reinforcement, steel arches (usually lattice guides), and soil reinforcement.

\section{Conclusions}

In this work, we used R.S data from India's national R.S agency to identify the land cover categorization of our city and how land use changes over time, as well as perform temporal analysis to assess the impact of climate on the surface in this thesis. All of these parameters were evaluated using the NDVI classification approach. This is a very quick and efficient form of investigation. It is widely used around the world for crop classification. However, because vegetation components are quite prominent in the photos, we utilized this one for land cover classification. Our primary goal is to conserve the city's vegetation for the sake of a healthy environment. All of the study's objectives that I established for it have been met. And the results that I discovered through our analysis are true up to 90 to 95 percent in the case of vegetation, around 85 to 90 percent in the case of structures, but the error percentage is much higher in the case of roads, free lands, and water, so the results are only true up to 60 to 70 percent. All of these classification errors can be decreased by employing highresolution, hyper-spectral photos from satellites, which the Indian government plans to launch in the future years. We may also use image analysis for the metro train project in Meerut and determine the shortest path for the metro train, which could be a solution to the city's traffic concerns. We recommend that all scientists employ image analysis techniques before beginning any underground operation that involves touching any building.

\section{References}

[1] Begni Gérard, Escadafal Richard, Fontannaz Delphine and Hong-Nga Nguyen Anne-Thérèse, 2005. Remote sensing: a tool to monitor and assess desertification. Les dossiers thématiques du CSFD. Issue 2. 44 pp.

[2] NASA (1986), Report of the EOS data panel, Earth Observing System, Data and Information System, Data Panel Report, Vol. IIa., NASA Technical Memorandum 87777, June 1986, 62 pp.

[3] C. L. Parkinson, A. Ward, M. D. King (Eds.) Earth Science Reference Handbook - - A Guide to NASA's Earth Science Program and Earth Observing Satellite Missions, National Aeronautics and Space Administration Washington, D.C.

[4] GRAS-SAF (2009), Product User Manual, GRAS Satellite Application Facility, Version 1.2.1, 31 March 2009.

[5] Anderson, J.T., Gregory, R.S. and Collins, W.T. (2002). "Acoustic classification of marine habitats in coastal Newfoundland." ICES Journal of Marine Science 59(1): 156-167.

[6] Andrieux, N., Delachartre, P., Vray, D., and Gimenez, G. (1995). "Lakebottom recognition using a wideband sonar system and time-frequency analysis." Journal of the Acoustical Society of America 98(1): 552-559.

[7] Anonymous. (2001a). "ECHOplus aids in seabed archaeology; one of the first seatronics products." Sea Technology 42(10): 69.

[8] Anonymous. (2001b). "ECHOplus sale to national Coral Reef Institute." Sea Technology 43(7): 59.

[9] Barnhardt, W.A., Kelley, J. T., Dickson, S.M. and Belknap, D.F. (1998). "Mapping the Gulf of Maine with Side-Scan Sonar: A New Bottom-Type Classification for Complex Seafloors." Journal of Coastal Research 14(2): 646-659.

[10] Bates, C.R. and Whitehead, E.J. (2001a). "ECHOplus measurements in Hopavågen bay, Norway." Sea Technology 42(6): 34 .

[11] Bates, C.R. and Whitehead, E.J. (2001b). "ECHOplus measurements in Hopavågen Bay, Norway." The Oceanography Society, Biennial Scientific Meeting, April 2001.

[12] Bax, N.J., Kloser, R.J., Williams, A., Gowlett-Holmes, K. and Ryan, T. (1999). "Seafloor habitat definition for spatial management in fisheries: a case study on the continental shelf of south east Australia using acoustic and biotic assemblages." Oceanologica Acta 22(6): 705-719.

[13] Baxter, K. and Bickers, A.N. (2004). "Characterising the Fish Habitats of the Recherche Archipelago." Final draft report: FRDC 2001/060 Habitat Mapping. G. Kendrick, University of Western Australia.

[14] Beaudoin, J., Hughes Clarke, J., van den Ameele, E. and Gardner, J. (2002). "Geometric and radiometric correction of multibeam backscatter derived from Reson 8101 systems." Proceedings of the Canadian Hydrographic Conference 2002, Canadian Hydrographic Association, Ottawa, Ontario, Summer, CD-ROM, pp. 8.

[15] Bennell, J.D. (2001). "Procedural Guideline No. 1-5 Mosaicing of sidescan sonar images to map seabed features." Marine Monitoring Handbook. J. Davies.

[16] Blondel, P. and Murton, B.J. (1997). Handbook of Seafloor Sonar Imagery. Chichester. John Wiley and Sons.

[17] Blondel, P., Parson, L.M. Robigou, V. (1998). "TexAn: Textural Analysis of Sidesacn Sonar Imagery and Generic Seafloor Characterisation." Proceedings of Oceans '98 vol. 2: 419-423.

[18] Blum, P., and Okamura, Y. (1992). "Pre-Holocene sediment dispersal systems and effects of structural controls and Holocene sea level rise from acoustic facies analysis: SW Japan Forearc." Marine Geology 108: 295-322.

Cite this article as: Antima, Sandeep Rana, A study on remote sensing data integrating multi spectral and their implementation in image analysis: a case study on metro train project of Meerut city, International journal of research in engineering and innovation (IJREI), vol 6, issue 1 (2022), 60-68 .https://doi.org/10.36037/IJREI.2022.6107. 